Acta Botanica Brasilica - 30(1): 35-40. January-March 2016.

\title{
Maternal habitat affects germination requirements of Anabasis setifera, a succulent shrub of the Arabian deserts
}

\author{
Ali El-Keblawy ${ }^{1,23^{*}}$, Sanjay Gairola ${ }^{3}$ and Arvind Bhatt ${ }^{4}$
}

Received: August 18, 2015

Accepted: October 13, 2015

\begin{abstract}
The effects of maternal habitat on light and temperature requirements during germination were assessed for the succulent desert shrub Anabasis setifera. Seeds were collected from the Mediterranean habitats of Egypt and the hyper-arid subtropical habitats of the United Arab Emirates (UAE). Seeds from the two populations were germinated in three temperature treatments in both a light/dark regime and continuous darkness. Seeds from the Egyptian population germinated significantly greater and faster than those of UAE. Seeds stored for four months at room temperatures have little dormancy and germinate at wide range of temperatures and light conditions, but seeds stored four months in the natural habitat lost their ability to germinate and rotted 10 days after incubation. The germination response to temperature depended on the habitat type. Seeds of the Egyptian population attained a significantly greater germination at lower temperatures, compared with seeds from the UAE population, but there was no difference in germination between the two populations at higher temperatures. Germination of $A$. setifera was very fast; most seeds germinated within four days. These results reflect the adaptive strategy of germination in both populations, and may help explain the wide distribution of this species in different climatic regions.
\end{abstract}

Keywords: Anabasis setifera, desert, halophyte, maternal habitat, seed germination

\section{Introduction}

Desert plants face severe environmental stresses, such as extremely high temperatures, very low erratic rainfall and high salinity (Kigel 1995). In order to enhance survival and fitness in such stressful environments, desert plants developed complementary sets of adaptation and survival strategies during different stages of their life cycles (Gutterman 2002; El-Keblawy 2004). For example, factors such as seed morphology, mass, wing size and persistence can all greatly affect the seed dispersal, dormancy and germination behavior of many desert plants (Xing et al. 2013; El-Keblawy et al. 2013; El-Keblawy \& Bhatt 2015).
The perianth structures such as wings, in fruits of many species of Chenopodiaceae have been considered as an important trait that determine the proper place of seed storage and time of germination and thus affects soil seed bank dynamics (Wei et al. 2008; Xing et al. 2013). The persistence of perianth after dispersal has been described as a strategy used to regulate seed germination level and timing in several desert species (Takeno \& Yamaguchi 1991; Wei et al. 2008; Xing et al. 2013).

The conditions under which seeds develop and mature on a maternal plant can determine the level and rate of seed germination and dormancy, which should affect time of germination and fate of next generation (Roach

\footnotetext{
${ }^{1}$ Department of Applied Biology, Faculty of Science, University of Sharjah, Sharjah, UAE

${ }^{2}$ Department of Biology, Faculty of Education in Al-Arish, Suez Canal University, Egypt

${ }^{3}$ Sharjah Seed Bank and Herbarium, Sharjah Research Academy, Sharjah, UAE

${ }^{4}$ Gulf Organization for Research \& Development, P.O. Box: 210162, Doha, Qatar

"Corresponding author: akeblawy@sharjah.ac.ae
} 
\& Wulff 1987; Baskin \& Baskin 1998; Meyer \& Allen 1999; El-Keblawy \& Al-Rawai 2006). Seed dormancy and germination requirements differ depending on maternal habitat, time of seed development and maturation on mother plants. For example, seed germination varies between populations of different species (El-Keblawy et al. 1996; Meyer \& Allen 1999; Gutterman 2000; ElKeblawy \& Al-Ansari 2000). In addition, environmental conditions experienced by maternal plants during the growing season have shown to play a significant role in determining subsequent germination responses in seeds of many species (Meyer \& Monsen 1991; El-Keblawy \& Al-Ansari 2000; Galloway 2002; Gutterman 2000). It is well established that temperature, rainfall, and day length are among the most important factors affecting maternal plants during the growing season (Roach \& Wulff 1987; Baskin \& Baskin 1998).

Fruits of some desert plants such as Haloxylon salicornicum, H. ammodendron and Salsola imbricata have persistent wings that help in seed dispersal and storage on soil surface (Huang et al. 2003; El-Keblawy 2013). Seeds of these plants germinate immediately after dispersal and consequently form a transient seed bank (Zaman \& Khan 1992; El-Keblawy 2013). Conversely, other desert halophytes such as Sporobolus ioclados, Diplachne fusca, Limonium axillare, Halocnemum strobilaceum and Halopeplis perfoliata produce small un-winged, non-dispersed seeds that are usually buried in the soil (Morgan \& Myers 1989; El-Keblawy 2013). Seeds of these species usually develop dormancy and form persistent seed bank (Morgan \& Myers 1989; Gulzar \& Khan 2002; Khan \& Gul 2006; Zia \& Khan 2008). Anabasis setifera Moq., another succulent desert facultative halophyte, however, produces fruits with wings that help them in dispersal but disintegrate shortly after landing on soil surface, leaving small rounded dark seeds. We noticed that seeds of $A$. setifera from a four-month soil bank were naked (i.e., perianths disintegrate) and stored in the top $10 \mathrm{~cm}$ of the soil (A El-Keblawy, unpubl. res.). It is not clear whether as a survival strategy $A$. setifera seeds would form a transient seed bank like halophytes with persistent wings or form a persistent seed bank like those that produce naked seeds.

Germination requirements are usually affected by environmental conditions that seeds face during development and storage (Roach \& Wulff 1987; Ooi et al. 2009; Fan et al. 2012; El-Keblawy \& Bhatt 2015). Seeds stored on soil surface face diurnal fluctuations in temperatures and are exposed to more light during storage, compared to small buried seeds that are stored at relatively more stable temperatures and in darkness (Moreno-Casasola et al. 1994; Nishimoto \& McCarty 1997; Zalamea et al. 2015). Little difference was observed between light and dark germination in winged seeds of some halophytes, such as Salsola imbricata (El-Keblawy et al. 2007) and Haloxylon salicornicum (El-Keblawy \& Al-Shamsi 2008). However, germination was very sensitive to light in species with small unwinged seeds of other halophytes, such as Halocnemum strobilaceum (Song et al. 2006; Qu et al. 2008), Amaranthus palmeri (Jha et al. 2010), Halopeplis perfoliata (El-Keblawy et al. 2015a). We hypothesized that seeds of A. setifera have high germination level like halophytes with winged fruits, but germination is sensitive to light, like halophytes with un-winged seeds, which bury in soil. The aim of the present study was to assess the light and temperature requirements for fresh and field-stored seeds of $A$. setifera from the Egyptian Mediterranean population and hyperarid subtropical UAE populations. We expect different germination behavior for $A$. setifera seeds matured under different environmental conditions of the Mediterranean and hyper-arid conditions. Studying the germination requirements for seeds from populations that differ greatly in environmental conditions would help in understanding the adaptations of this species to survive under wide range of environmental conditions.

\section{Materials and Methods}

Anabasis setifera Moq. (Amaranthaceae) is a perennial dwarf succulent shrub, widely distributed in Egypt, Arabia, Iran, Afghanistan, Pakistan and India (Ali 1978). It produces winged fruits (hereafter referred as seeds) that are dispersed by wind (Lev-Yadun et al. 2009). The wings - about 3 - $4 \mathrm{~mm}$ in diameters-are not persistent and disintegrates shortly after dispersal. Every fruit carry a tiny seed; average mass of 1000 seeds is 0.43 and 0.28 $\mathrm{g}$ for the Egyptian and UAE populations, respectively (ElKeblawy et al. 2015b). Seeds of A. setifera usually mature in November and December and disperse predominantly between December and early January. The time of seed dispersal coincides with the time of onset of rainfall and consequently seeds germinate immediately after dispersal.

Seeds of A. setifera were collected from Seih Shuaib, Abu Dhabi, UAE (24 $\left.{ }^{\circ} 53^{\prime} 43.16^{\prime \prime} \mathrm{N}, 54^{\circ} 55^{\prime} 49.45^{\prime \prime} \mathrm{E}\right)$ and the eastern region of Cairo at Cairo - Suez road $\left(30^{\circ} 6^{\prime} 20.45^{\prime \prime} \mathrm{N}\right.$, $\left.31^{\circ} 35^{\prime} 21.48^{\prime \prime} \mathrm{E}\right)$, Egypt. The climate of the UAE is arid subtropical with high temperatures, but that of Egypt is semi-arid Mediterranean with moderate temperatures. The nearest meteorological station to the study Egyptian population (Cairo Airport) indicates that the average annual rainfall is around $100 \mathrm{~mm}$. Most of rain falls during the period between November and April with December. The average low and high minimum temperature ( 8 and $19^{\circ} \mathrm{C}$, respectively) is in January and the average low and high maximum temperature $\left(23\right.$ and $36^{\circ} \mathrm{C}$, respectively) is present in both July and August (www.worldweatheronline.com). In the UAE, the nearest station to the study population (Dubai Airport) indicates that the average total annual rainfall is $84.3 \mathrm{~mm} ; 85 \%$ of it precipitated between December and March. Average minimum temperature is $14.3^{\circ} \mathrm{C}$ in January and the average maximum tempera- 
ture is $41.3^{\circ} \mathrm{C}$ in August (https://services.dubaiairports. ae/dubaimet/MET/Climate.aspx). The average electrical conductivity of the Egyptian and UAE population was 0.52 and $17.5 \mathrm{~ms} / \mathrm{cm}$, respectively. In addition, the $\mathrm{pH}$ was 8.0 and 7.3 in the Egyptian and UAE populations, respectively (A El-Keblawy unpubl. res.).

Matured seeds on shrub canopies were collected during the last week of December 2013 from both populations and again from under the shrubs' canopy after four months following dispersal (April 2014). Immediately after collection, fresh seeds were stored in brown paper bags at room temperature $\left(20 \pm 2^{\circ} \mathrm{C}\right)$ until the experiment started in the third week of April 2014. Seeds were collected from 50-60 randomly chosen plants and mixed together in order to represent the genetic diversity of the populations.

Seeds of A. setifera collected from the two populations during both December 2013 and April 2014 were germinated at daily night/day temperature regimes of $15 / 25^{\circ} \mathrm{C}$, $20 / 30^{\circ} \mathrm{C}$ and $25 / 35^{\circ} \mathrm{C}$ in both continuous darkness and alternating $12 \mathrm{~h}$ light $/ 12 \mathrm{~h}$ darkness. The light period coincided with the higher temperature. In dark treatment, the petri-dishes were wrapped in aluminium foil to prevent any exposure to light. The germination was conducted in 9-cm tight-fitting petri-dishes containing one disk of Whatman No. 1 filter paper moistened with $10 \mathrm{ml}$ of distilled water. Three replicates, each with 35 seeds, were used for each treatment. Seeds were considered to be germinated with the emergence of the radicle. Germinated seeds were counted and removed every alternate day, for 14 days. However, seeds incubated in the dark were checked only after 14 days. Most of the germination occurred within 10 days following sowing and consequently we decided to stop seedlings counting after 14 days. All the un-germinated seeds were rotted after 10 days of incubation, indicating that they are not viable. A tetrazolium test had confirmed this.

\section{Data analysis}

Rate of germination was calculated with a modified Timson's germination velocity index: $\Sigma \mathrm{G} / \mathrm{T}$, where $\mathrm{G}$ is the percentage of seed germinated on every day, and $\mathrm{T}$ is the total germination period (Khan \& Ungar 1998). The maximum possible value for our data using this germination rate index (GRI) was 50 . The higher the value the more rapid the germination. The germination rate was only calculated for seeds incubated under light conditions.

As no germination occurred for seeds collected during April 2014 from the natural habitats of both the Egyptian and UAE populations, the results of these collections were excluded from data analysis. Three-way ANOVA was used to assess the significance of the main factors (maternal habitat, and temperature and light of incubation) and their interactions on final germination. Two-way ANOVA was used to assess the impact of maternal habitat and temperature of incubation and their interactions on the germination rate index (GRI). Tukey test (Honestly significant differences, HSD) was used to estimate least significant range between means. The germination rate was log-transformed and germination percentages were arcsine-transformed to meet the assumptions of ANOVA. This transformation improved normality of the distribution of the data. All statistical methods were performed using SYSTAT, version 13.0.

\section{Results}

There was no germination for seeds collected after four months following dispersal (i.e., April 2014) from the natural habitats of both the Egyptian and UAE populations (data not shown). The effects of maternal habitat, temperature and light of incubation on final germination percentage of $A$. setifera were significant $(\mathrm{P}<0.01)$. However, there was no significant effects for the interactions between light and both maternal habitat and temperature and their interaction ( $P>0.05$, Tab. 1$)$. Generally, seeds from the Egyptian population attained significantly higher germination $(66.4 \pm 3.7 \%)$, compared to seeds from the UAE population ( $42.4 \pm 2.0 \%$ ). In addition, germination at lower temperatures $\left(15 / 25\right.$ and $\left.20 / 30^{\circ} \mathrm{C}\right)$ was significantly greater than at higher temperature $\left(25 / 35^{\circ} \mathrm{C}\right)$. Furthermore, germination was significantly greater in light/dark regime $(58.9 \pm 3.9 \%)$ than in darkness $(50.0 \pm 4.2 \%)$.

Table 1. Three way ANOVA showing the effects of maternal habitat, and temperature and light of incubation on final germination percentage of $A$. setifera seeds.

\begin{tabular}{|c|c|c|c|c|}
\hline Source of variation & df & Mean Squares & F-Ratio & p-Value \\
\hline Habitat (H) & 1 & 0.860 & 98.130 & $<0.001$ \\
\hline Temperature (T) & 2 & 0.140 & 15.973 & $<0.001$ \\
\hline Light (L) & 1 & 0.109 & 12.446 & $<0.01$ \\
\hline $\mathrm{H}^{*} \mathrm{~T}$ & 2 & 0.203 & 23.138 & $\mathrm{n}$ \\
\hline $\mathrm{H}^{*} \mathrm{~L}$ & 1 & 0.000 & 0.008 & $\mathrm{~ns}$ \\
\hline $\mathrm{T}^{*} \mathrm{~L}$ & 2 & 0.001 & 0.110 & $\mathrm{~ns}$ \\
\hline $\mathrm{H}^{*} \mathrm{~T}^{*} \mathrm{~L}$ & 2 & 0.005 & 0.579 & $\mathrm{~ns}$ \\
\hline Error & 24 & 0.009 & & \\
\hline
\end{tabular}


The germination response to temperature of incubation depended on the habitat type; the interaction between maternal habitat and temperature was significant $(\mathrm{P}<0.001$, Tab. 1). No significant difference was observed in germination between seeds of the UAE $(42.7 \pm 2.0 \%)$ and Egypt $(49.3 \pm 2.2 \%)$ at the higher temperatures $(25 / 35$ $\left.{ }^{\circ} \mathrm{C}\right)$. However, germination at lower $\left(15 / 25^{\circ} \mathrm{C}\right)$ and moderate $\left(20 / 30{ }^{\circ} \mathrm{C}\right)$ temperatures was significantly greater for seeds of the Egyptian population $(67.3 \pm 3.2 \%$ and 82.7 $\pm 3.7 \%)$, compared with seeds from UAE $(46.0 \pm 2.9 \%$ and $38.7 \pm 4.3 \%$, respectively) (Fig. 1 ).

Germination of A. setifera was very fast; most seeds of the Egyptian and UAE populations were germinated within two and four days, respectively. There was a significant effect for the maternal habitat $\left(\mathrm{F}_{1,12}=11.35, \mathrm{P}<0.001\right)$, but not for temperature of incubation $\left(\mathrm{F}_{2,12}=1.20, \mathrm{P}>0.05\right)$ or the interaction between temperature and maternal habitat $\left(\mathrm{F}_{2,12}=0.18, \mathrm{P}>0.05\right)$ on the germination rate index. Germination was significantly faster for the Egyptian seeds (GRI $=48.6 \pm 0.4$ ), compared with that of UAE seeds (GRI $=43.3 \pm 1.4$ ) (Fig. 2 ).
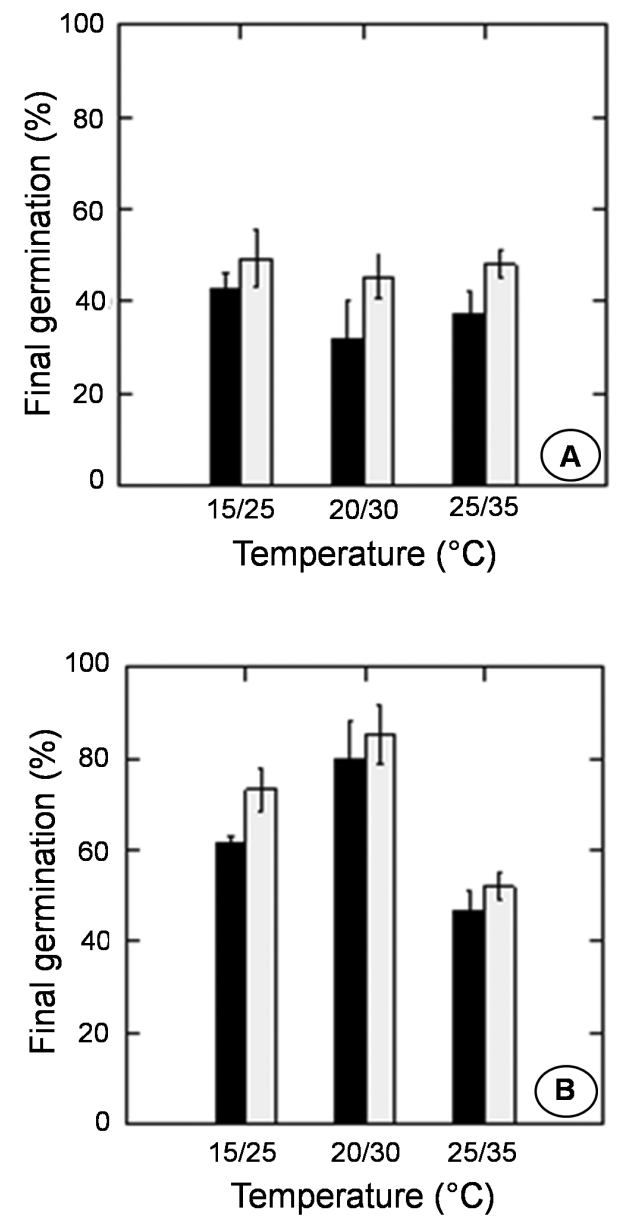

Figure 1. Effects of maternal habitat, and temperature and light of incubation on final germination percentage (mean $\pm S E$ ) of $A$. setifera seeds from (A) United Arab Emirates and (B) Egyptian populations. Black bar = dark germination, light bars $=$ light germination

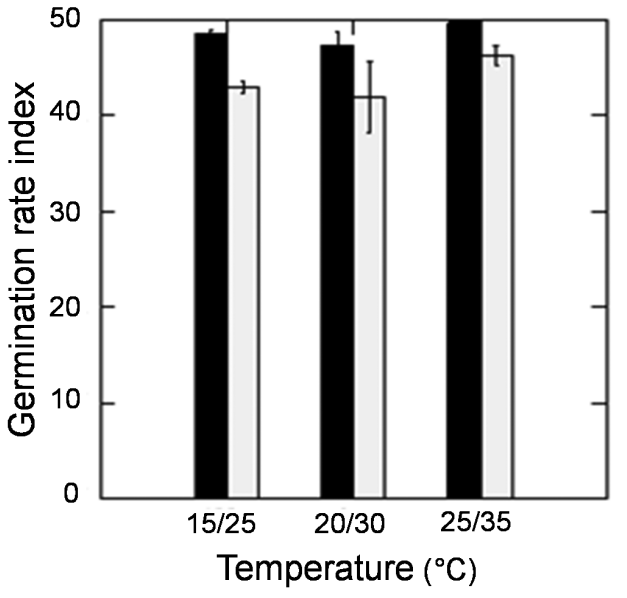

Figure 2. Effects of maternal habitat and temperature of incubation on germination rate (expressed as mean $\pm \mathrm{SE}$ of germination rate index) of $A$. setifera seeds. Black bars = Egypt seeds, and light bars = United Arab Emirates seeds

\section{Discussion}

Plant species that grow in different geographical regions might experience different local environmental conditions due to climatic, soil and other habitat differences (Tieu et al. 2001). The studied species A. setifera experiences different environmental conditions in the habitats of Egypt and UAE. The climate is mild Mediterranean in Egypt, but dry hyper-arid in the UAE. Such a large difference in maternal habitats has affected germination level and speed. However, there were no significant effects for the interaction between maternal habitat and light and the interaction between maternal habitat, light and temperature of incubation. The lack of significant interactions indicates the ability of the seeds of A. setifera to germinate in wide range of environmental conditions. This would explain the wide range of distribution of this species in different climatic regions.

Seeds of the Egyptian population germinated significantly greater at lower temperatures compared with seeds from the UAE population. Such results could be an ecological adaption for the survival of $A$. setifera in the habitats of the two populations. Egyptian site has much lower temperatures during the time of seedling emergence, compared with that of the UAE. Seeds of both populations mature and germinate immediately after dispersal in December and January. In the Egyptian site, the minimum and maximum temperatures are 11 and $21^{\circ} \mathrm{C}$ during December and 8 and $19^{\circ} \mathrm{C}$ during January. However, the minimum and maximum temperatures in the UAE site are 16 and $24.1^{\circ} \mathrm{C}$ in December and 14.2 and $22^{\circ} \mathrm{C}$ during January (Feulner 2006). This suggests that the requirement for lower temperatures in the Egyptian seeds would enhance their ability to germinate during December and January. However, there was no significant difference in 
the germination between the two populations at higher temperatures $\left(25 / 35^{\circ} \mathrm{C}\right)$. Such higher temperatures usually prevail during March and April in the UAE and during April and May in Egypt. During these months, no germination will take place in both populations, if rainfall happens. As evident from our results, seeds collected from the field at April did not germinate.

The present study indicated that seeds collected after four months of dispersal from natural habitats were not able to germinate and consequently did not form persistent seed bank. This phenomenon has been reported in many other succulent desert shrubs with seeds able to germinate immediately and disperse over long distances with the aid of winged perianths (e.g., Salsola imbricata and Haloxylon salicornicum - El-Keblawy 2013; Haloxylon stocksii - Gulzar \& Khan 2001; Haloxylon ammodendron - Huang et al. 2003). El-Keblawy (2013) reported three reasons that would explain the transient nature of seed bank of above-mentioned desert shrubs. Firstly, maintenance of seed dormancy when conditions are optimal for germination can be a disadvantage in some species as seeds are exposed to lethal environmental factors such as granivory and extreme temperatures for longer periods. This is particularly true for seeds with winged perianth that keep them exposed to extreme diurnal temperatures and moisture fluctuations on soil surface. Secondly, species with non-dormant seeds might be expected to benefit from earlier germination more than those with dormant seeds. In general, Verdú \& Traveset (2005) have also reported that the early emergence increase seedling survival, growth, and fecundity. Finally, seed storage might reduce germination speed, which usually reduce the competitive ability of the seedlings, as they emerge later in the season, compared to other species (Rees 1996; Zia \& Khan 2004). The high annual fruit production in A. setifera should compensate the high seed mortality rate. This species produce enormous amount of highly dispersed fruits every year (roughly several hundreds of thousands), even in the dry seasons (El-Keblawy 2013). A. setifera plants rely mainly on atmospheric moisture and fog as main sources of water for their growth.

The results indicated that the germination of A. setifera was very fast; most seeds of the Egyptian and UAE populations were germinated within two and four days, respectively. Parsons (2012) reported 20 species of the family Amaranthaceae that have very fast germination rate. He indicated that the embryo cells of the seeds of these species elongate and the spiral embryo uncoils and ruptures within 10 minutes after imbibition. Fast germination has been considered as a strategy to utilize the brief period of water availability and ensure rapid seedling growth, early in the growing season, which can minimize competition (El-Keblawy \& El-Shamsi 2008; El-Keblawy et al. 2007). Seedling coming earlier in the season can rapidly exploit temporarily favourable conditions for ger- mination (Parsons 2012). Although rapid germination is an opportunistic strategy to cope with little precipitation and unpredictable rainfall of the deserts, it represents a high risk strategy as the established seedlings might die if no precipitation happen after seedling establishments (Gutterman 2012).

In conclusion, the study indicated that seeds of $A$. setifera can germinate in a wide range of environmental conditions that enable it to grow in different climatic conditions. Maternal habitats significantly affected temperature requirements during germination. Seeds collected from the natural habitats were not able to germinate after four months of their production. Therefore, further studies are needed to explain the transient nature of seed bank of this species.

\section{Acknowledgements}

We thank the Gulf Organization for Research and Development for their facilities and support. This work was supported through a grant from the Qatar National Research Fund, QNRF (Grant \# 5-260-1-053).

\section{References}

Ali SI. 1978. The Flora of Pakistan: some general and analytical remarks. Notes from the Royal Botanic Garden Edinburgh 36: 427-439.

Baskin CC, Baskin JM. 1998. Seeds: ecology, biogeography, and evolution of dormancy and germination. San Diego, Academic Press.

El-Keblawy A. 2004. Salinity effects on seed germination of the common desert range grass, Panicum turgidum. Seed Science and Technology 32: 873-878.

El-Keblawy A. 2013. Effects of seed storage on germination of two succulent desert halophytes with little dormancy and transient seed bank. Acta Ecologica Sinica 33: 338-343.

El-Keblawy A, Al-Ansari F. 2000. Effect of site of origin, time of seed maturation and seed age on germination behavior of Portulaca oleracea L. from old and new world. Canadian Journal of Botany 78: 279-287.

El-Keblawy A, Al-Ansari F, Hassan N, Al-Shamsi N. 2007. Salinity, temperature and light affect germination of Salsola imbricata. Seed Science and Technology 35: 272-281.

El-Keblawy A, Bhatt A. 2015. Aerial seed bank affects germination in two small-seeded halophytes in Arab Gulf desert . Journal of Arid Environment 117: 10-17.

El-Keblawy A, Bhatt A, Gairola S. 2013. Perianth colour affect germination behavior in the wind pollinated Salsola rubescens in the Arabian Deserts. Canadian Journal of Botany 92: 69-75.

El-Keblawy A, Bhatt A, Gairola S. 2015a. Storage on maternal plants affects light and temperature requirements during germination in two small seeded halophytes in the Arabian deserts. Pakistan Journal of Botany: 47: 1701-1708.

El-Keblawy A, Bhatt A, Gairola S. 2015b. Maternal salinity environment affects salt tolerance during germination in Anabasis setifera: A facultative desert halophyte. Journal of Arid Land (in press).

El-Keblawy A, Al-Rawai A. 2006. Effects of seed maturation time and dry storage on light and temperature requirements during germination in invasive Prosopis juliflora. Flora 201: 135-143.

El-Keblawy A, Shaltout KH, Lovett-Doust J, Lovett-Doust L. 1996. Maternal effect on progeny in Thymelaea hirsuta. New Phytologist 132: 77-85. 
El-Keblawy A, Al-Shamsi N. 2008. Salinity, temperature and light affect seed germination of Haloxylon salicornicum, a common perennial shrub of the Arabian deserts. Seed Science and Technology 36: 679-688.

Fan JW, Du YL, Turner NC, Li FM, He J. 2012. Germination characteristics and seedling emergence of switchgrass with different agricultural practices under arid conditions in China. Crop Science 52: 2341-2350.

Feulner GR. 2006. Rainfall and climate records from Sharjah Airport: Historical data for the study of recent climatic periodicity in the UAE. Tribulus 16: 3-9.

Galloway LF. 2002. The effect of maternal phenology on offspring life history in the herbaceous plant Campanula americana. Journal of Ecology 90: 851-858.

Gulzar S, Khan MA 2001. Seed germination of a halophytic grass Aeluropus lagopoides. Annals of Botany 87: 319-324.

Gulzar S, Khan MA. 2002. Alleviation of salinity-induced dormancy in perennial grasses. Biologia Plantarum 45: 617-619.

Gutterman Y. 2000. Maternal effects on seeds during development. In: Fenner M. (ed.) Seeds: The Ecology of Regeneration in Plant Communities. Wallingford, UK CAB International. p. 59-84.

Gutterman Y. 2002. Survival strategies of annual desert plants. Adaptations of desert organisms. New York, Springer, Berlin Heidelberg.

Gutterman Y. 2012. Seed germination in desert plants. Berlin and Heidelberg, Springer-Verlag.

Huang Z, Zhang XS, Zheng GH, Gutterman Y. 2003. Influence of light, temperature, salinity and storage on seed germination of Haloxylon ammodendron. Journal of Arid Environment 55: 453-464.

Jha P, Norsworthy JK, Riley MB, Bridges Jr W. 2010 Annual changes in temperature and light requirements for germination of Palmer amaranth (Amaranthus palmeri) seeds retrieved from soil. Weed Science 58: 426-432.

Khan MA, Gul B. 2006. Halophyte seed germination. In: Khan MA, Weber DJ. (eds.) Ecophysiology of High Salinity Tolerant Plant spp. The Netherlands, Springer Publications. p.11-30.

Khan MA, Ungar IA. 1998. Effect of thermoperiod on recovery of seed germination of halophytes from saline conditions. American Journal of Botany 84: 279-283.

Kigel J. 1995. Seed germination in arid and semiarid regions. In: Kigel J, Galili G. (eds.) Seed development and germination. New York, Marcel Dekker. p. 645-699.

Lev-Yadun S, Neeman G, Izhaki I. 2009. Unripe red fruits may be aposematic. Plant Signaling and Behavior 4: 836-841.

Meyer SE, Allen PS. 1999. Ecological genetics of seed germination regulation in Bromus tectorum L. II. Reaction norms in response to a water stress gradient imposed during seed maturation. Oecologia 120: 35-43.

Meyer SE, Monsen SB. 1991. Habitat-correlated variation in mountain big sagebrush (Artemisia tridentate ssp. vaseyana) seed germination patterns. Ecology 72: 739-724.

Moreno-Casasola P, Grime JP, Martinez ML. 1994. A comparative study of the effects of fluctuations in temperature and moisture supply on hard coat dormancy in seeds of coastal tropical legumes in Mexico. Journal of Tropical Ecology 10: 67-86.
Morgan WC, Myers BA. 1989. Germination of the salt-tolerant grass Diplachne fusca. I. Dormancy and temperature responses. Australian Journal of Botany 37: 225-237.

Nishimoto RK, McCarty LB. 1997. Fluctuating temperature and light influence seed germination of goosegrass (Eleusine indica). Weed Science 45: 426-429.

Ooi MK, Auld TD, Denham AJ. 2009. Climate change and bet-hedging: interactions between increased soil temperatures and seed bank persistence. Global Change Biology 15: 2375-2386.

Parsons RF. 2012. Incidence and ecology of very fast germination. Seed Science Research 22: 161-167.

Qu XX, Huang ZY, Baskin JM, Baskin CC. 2008. Effect of temperature, light and salinity on seed germination and radicle growth of the geographically widespread halophyte shrub Halocnemum strobilaceum. Annals of Botany 101: 293-299.

Rees M. 1996. Evolutionary ecology of seed dormancy and seed size. Philosophical Transactions of the Royal Society of London 351: 1299-1308.

Roach DA, Wulff R. 1987. Maternal effects in plants. Annual Review of Ecology, Evolution, and Systematics 18: 209-235.

Song J, Feng G, Zhang F. 2006. Salinity and temperature effects on germination for three salt-resistant euhalophytes, Halostachys caspica, Kalidium foliatum and Halocnemum strobilaceum. Plant and Soil 279: 201-207.

Takeno K, Yamaguchi H. 1991. Diversity in seed germination behavior in relation to heterocarpy in Salsola komarovii Iljin. Botanical Magazine (Tokyo) 104: 207-215.

Tieu A, Dixon KW, Meney KA, Sivasithamparam K, Barrett RL. 2001. Spatial and developmental variation in seed dormancy characteristics in the fire-responsive species Anigozanthos manglesii (Haemodoraceae) from Western Australia. Annals of Botany 88: 19-26.

Verdú M, Traveset A. 2005. Early emergence enhances plant fitness: a phylogenetically controlled meta-analysis. Ecology 86: 1385-1394.

Wei Y, Dong M, Huang ZY, Tan DY. 2008. Factors influencing seed germination of Salsola affinis (Chenopodiaceae), a dominant annual halophyte inhabiting the deserts of Xinjiang, China. Flora 203:134-140.

Xing J, Cai M, Chen S, Chen L, Lan H. 2013. Seed germination, plant growth and physiological responses of Salsola ikonnikovii to shortterm $\mathrm{NaCl}$ stress. Plant Biosystems 147: 285-297.

Zalamea PC, Sarmiento C, Arnold AE, Davis AS, Dalling JW. 2015. Do soil microbes and abrasion by soil particles influence persistence and loss of physical dormancy in seeds of tropical pioneers? Frontiers in Plant Science 5: 799.

Zaman AU, Khan MA. 1992. The role of buried viable seeds in saline desert community. Bangladesh Journal of Botany 21: 1-10.

Zia S, Khan MA. 2004. Effect of light, salinity, and temperature on seed germination of Limonium stocksii. Canadian Journal of Botany 82: 151-157.

Zia S, Khan MA. 2008. Seed germination of Limonium stocksii under saline conditions. Pakistan Journal of Botany 40: 683-695. 